\title{
The Effects of Mood and Emotion on Consumer Purchase Behavior of Buying Clothes
}

\author{
Sepideh Samadi
}

\begin{abstract}
The way people purchase dresses is an impact of how their mood and emotion on daily bases. The purpose of this research is to investigate the psychological reasons of how individuals' mood and emotion influence their purchase behavior on choosing a clothes, and how it shows their personality, mood and emotion and the relationships connecting clothing style, preference, emotions and mood. The result specifies strong relationships between mood and important relationships among clothing preference and an individual's emotion. Mood was an important predictor of preference, at the same time as emotional feeling was restrained. The methodology derivative from a specific number of sample sizes by analyzing both quantitative and qualitative methods. This is a vital demonstration of how important this combination is in order to fully be pleased about the psychological profile of emotion and mood of the fashion consumers.
\end{abstract}

Keyword: Consumer Behavior, Clothing, Emotion, Mood

\section{INTRODUCTION}

$\mathrm{H}$ behind every single action a person takes, sometimes no action is taken, instead less explicit ways are chosen to convey meanings, such as body movements, changing the way they speak or how they dress. It is a universal phenomenon that mood and emotion has an effect on the way consumers purchase clothing. One's attire or dressing style is said to be an important part of the personality representation as it gives the first impression on the others, though emotion and mood are two factors of a person's personality which clothing can have impact on. On the other hand, it is widely accepted that clothing has the potential and is commonly used to reflect and convey the inner self, e.g. self image, mood, social aspirations etc; but also that consumers prefer products that are consistent with their identity. This can happen without one's own realization, by their sub-conscious mind, the person just feels like dressing in a certain way. Understanding this connection is important because the way a person chooses to dress can affect their everyday life in numerous ways. The circle of friends and associates, job interview performance or how a person feels, all of these person decides to wear on daily bases. Many studies have investigated mood and personality but are out of date, and do not consider the causal relationships. The knowledge regarding this connection can be used as an advantage by purposefully dressing in a certain way or to help better understand how people's emotion and mood influence the way they choose to dress. Dress and physical appearance are

Revised Manuscript Received on October 31, 2019

* Correspondence Author

SepidehSamadi, PhD Candidate, University of Bolton, Business Faculty and Professional Development Rep, American College of Dubai, Dubai, UAE. Email: samadisep@gmail.com shape the future of one's life and are affected by what the

two variables which emphasize the degree of importance placed on the body as means of self-expression.

This research aims to investigate the psychological factors that affect the way people purchase clothing and how their mood and emotion influence their decision making in buying clothes. First a literature review is conducted in order to discover and explain the latest related findings and then a questionnaire is prepared and distributed to extract new knowledge from the results. As the fashion market continues to fragment, a deeper understanding of the consumer's psychological profile would help develop more targeted strategies for retailers as well.

\section{A. Rationale and Significance}

The main objective of this study is to identify the connection of psychological aspects of moods and emotion and the specific objectives are to identify the impact of emotion and mood on purchase behavior on buying clothing. It measures the influence of the factors toward the sample size in choosing their cloths and how their mood and emotion affects their purchase behavior and the strength of relationships among the variables.

In addition, this research paper aims to examine the psychological factors that affect the way people dress and how it is connected to their personality, mood and emotions. The knowledge regarding this connection has several benefits. Fashion retailers can use this knowledge in order to design their decorations and clothing in a way that maximizes consumer satisfaction and buying potential which can in turn, maximize their sales. Companies can use this knowledge to design their staff clothes in a way to improve employee mood and therefore, productivity; the same thing can be performed in events to maximize crowd happiness.

\section{LITERATURE REVIEW}

One factors of preference that has been identified is the affective component. The affective component covers the motions and the positive and negative responses of mood (Moody, Kinderman\&Sinha, 2010). Moody, Kinderman and Sinha conducted a study to explore connections between clothing styles, preference, personality factors, emotions and mood with the aim of reaching a better understanding of fashion consumer psychology. In order to accurately measure the mood of participants, they used the PANAS questionnaire developed by Watson, Clark and Carey (1980). In their research they use the five factor model to explain the personality of a person. Based on their research they found out that both mood and personality played a role in the person's choice of clothing style but mood had a more significant effect.
Blue Eyes Intelligence Engineering \& Sciences Publication 


\section{The Effects of Mood and Emotion on Consumer Purchase Behavior of Buying Clothes}

Personality traits had a lower effect on clothing style because out of the eight clothing pieces provided to participants, only three showed moderate to strong relationship with certain personality traits. Aside from the mentioned, main findings, they were also able to confirm findings of pervious authors regarding the ability of clothing to alter and manage mood, for example, when participants were in a bad mood and given a loose and oversized clothing, their moods improved while on the other hand, if they had a high mood and were given the same clothing, their moods were adversely affected. They utilized several different methods of research in order to reach these findings but the complexity, expensiveness, equipment availability and the required time commitment from participants made the sample size small which makes any generalized conclusion quite unreliable.

Raunio, identified three factors in the preference of clothing: physical features of cloths including skin response, size and shape of the clothes, thermal comfort, and fit, revealing levels and visual features; the wearers' self-appearance; and associative reasons and memories. All of these factors would generate an emotional response.

Asare, Ibrahim and Kwesi (2016) researched about social and psychological factors that influenced female students' choice of clothing, they found out that body image played an important role in the selection of clothing. More specifically, the female students preferred clothing that emphasized the body parts that they were satisfied with. Since body image is related to neuroticism personality trait, it can be inferred that personality plays a role in what people choose to wear (Allen and Walter). The research was not as focused on psychological aspects as it was on social and other factors which is why there isn't a significant amount of findings reported, and also, the questions that were included in the questionnaire weren't written well enough to facilitate proper psychology related knowledge extraction.

Kang, Johnson and Kim (2013) conducted a study on three hundred and ten undergraduate women from Midwestern University in USA, which aimed to examine the possibility of altering mood by studying a person's personality traits, social anxiety and clothing functions. They utilized the five factor model to describe people's personality.

Kwon and Parham (1994) used the term clothing functions in order to identify the multiple purposes of a single clothing item, these purposes were labeled as: fashion, camouflage, individuality, comfort and assurance. Clothing items with higher clothing functions had a strong positive relation with a person's mood, in the sense that, if clothing item was highly fashionable and high individuality, it would boost the person's mood higher than a clothing item that had only one clothing function. In this research paper, they were able to find a connection between people with social anxiety and having a high neuroticism personality trait, and found that they prefer comfortable clothes that hide their appearance flaws (camouflage). Similarly, people who feel a close connection between themselves and what they wear prefer clothes that can hide their appearance flaws while being fashionable and unique (individuality). These findings show that a person's personality traits and how they perceive themselves, affects how they choose to dress. The paper's results cannot be generalized too broadly because even though the sample size is quite large, it is chosen based on convenience and as a result contains a small demographic diversity.

\section{A. Clothing, Emotion and Mood}

Clothing, known as an aesthetic self and body image management tool and mood, is not a new idea of studying, but clothing as mediating the relationship between clothing satisfaction with self-perception (of sociability, emotional stability, and dominance), is more recent. It is our contention that clothing, clothing attributes or garment features can affect positive and negative moods and individual emotions. Humphrey et al., and Worrell (2010), showed how clothing can be used to express positive emotions or as a coping mechanism to overcome negative self-concepts. Although depression has been linked to a lack of concern for personal appearance, studies have also shown that closer interest in clothing can correlate with increased depression; but also that over even short periods after dressing; cloths can lift or change a low mood. Laros\&Steenkamp (2003) found that we choose clothing daily to cope with social circumstances and one's feelings. She observed that expressive features of favorite clothes helped to create a feeling of togetherness with other people, to stand out, produce an impression and control feelings, images and impressions of others. She indicated that favorite clothes are important for controlling one's emotions and mood.

Furthermore, Kwon (2015) demonstrated the relationships between the perception of mood, self-consciousness and the selection of clothing concluding that females were more sensitive to mood than men, who affected their clothing choices; and the negative moods affected their choices more than positive moods.

\section{B. Research Objective}

Choosing clothes always have an impact on the mood of an individual. After discussing related to the literature reviews that have been conducted by several researchers, the objective of this paper is to explore the effect of clothing on people's mood and emotion, its aim is to find the relationship between clothing style, emotions and mood with a view to a better understanding of the psychological profile of the fashion consumers.

\section{RESEARCH METHODOLOGY}

The research question that has been used in this paper in order to reach to the final objective is "How does the choice of clothing affect one's moods and emotions?" Survey questionnaire has been distributed and the total of responses from the participants was 66. Participant's data was entered in Google forms and calculate in Microsoft Excel.

The data to conduct this research was gathered by preparing and distributing a questionnaire, to an audience of thirty to forty people, in the Bay Square area, around the College of Fashion and Design campus. As a result, the research method will be quantitative and based on the analyses of the questionnaire answers. Qualitative and quantitative analysis was done to the above mentioned samples size in which both aspects was being considered in the research findings section. The chosen sample size was somehow small in number and as such can partially be assumed to be representative of the population. 
Though the questionnaire was being distributed in a new location in Dubai, where all people who are working there are fashionable and the reason to choose that place as a location of survey distribution was the fact that it could give better sample population of a different variety of population; from students to employees, though the topic can be related to the people's style and their work place. However, from this sample, the findings imply that clothing is used as an appearance and mood management tool by reflecting or managing positive or negative mood.

\section{RESULTS AND FINDINGS}

\section{A. Demographic Data of the Respondents}

From the research methodology and from the number of 66 participants, table 1 presents the demographical data of the respondents. The first section of the questionnaire comprised seven questions on the demography. There was total of 4 $(6.1 \%)$ males and $62(93.9 \%)$ females who has participated in this research. Among which $33.3 \%$ belongs to the $30-40$ years age group, $28.8 \%$ belongs to the $40-50$ years age group, $27.3 \%$ belongs to the $20-30$ years age group, $9.1 \%$ belongs to the 50 or above years age group and $1.5 \%$ belongs the less than 20 years age group.In addition, $62.1 \%$ of respondents had bachelor's degree while $21.2 \%$ had master's degree, $12.1 \%$ had high school diploma and $4.5 \%$ had $\mathrm{PhD}$ or above.Overall, $36.4 \%$ of respondents were working full-time, $36.4 \%$ were unemployed, $16.7 \%$ were working part-time and $10.6 \%$ were student. Majority of the respondents were married $(75.8 \%)$ and only $24.2 \%$ were single. The largest group of respondents $86.3 \%$ weren't wearing a uniform to work and $13.7 \%$ wore a uniform to work.

Characteristic Number of Percentage Respondents

\begin{tabular}{|c|c|c|}
\hline Age & & \\
\hline Less than 20 & 1 & 1.5 \\
\hline $20-30$ & 18 & 27.3 \\
\hline $30-40$ & 22 & 33.3 \\
\hline $40-50$ & 19 & 28.8 \\
\hline 50 or above & 6 & 9.1 \\
\hline Education & & \\
\hline Less than high & 0 & 0 \\
\hline school & 8 & 12.1 \\
\hline High school & 41 & 62.1 \\
\hline Bachelor Degree & 14 & 21.2 \\
\hline Master's Degree & 3 & 4.5 \\
\hline $\mathrm{PhD}$ or above & & \\
\hline Working Status & & \\
\hline Full-Time & 24 & 36.4 \\
\hline Part-Time & 11 & 16.7 \\
\hline Unemployed & 24 & 36.4 \\
\hline Student & 7 & 10.6 \\
\hline Marital Status & & \\
\hline Single & 16 & 75.8 \\
\hline Married & 50 & 24.2 \\
\hline $\begin{array}{l}\text { Wearing Uniform } \\
\text { for Work }\end{array}$ & 7 & 13.7 \\
\hline Yes & 44 & 86.3 \\
\hline No & & \\
\hline Gender & & \\
\hline Male & 4 & 6.1 \\
\hline Female & 62 & 93.9 \\
\hline
\end{tabular}

\begin{tabular}{l|cc} 
Nationality & & \\
UAE National & 64 & 97 \\
Non- UAE & 2 & 3 \\
National & & \\
\hline
\end{tabular}

Table 1 Respondents Demographic Data

Questionnaire items were analyzed using Microsoft Excel. Participants were asked to rate each statement on a 5 point scale of agreement ranging from $1=$ strongly disagree through $3=$ neither agree nor disagree to $5=$ strongly agree .

\begin{tabular}{|c|c|c|}
\hline QUESTION & Mean & SD \\
\hline $\begin{array}{l}\text { certain clothes } \\
\text { make me feel } \\
\text { good about } \\
\text { myself. }\end{array}$ & $\begin{array}{c}4.54545454 \\
5\end{array}$ & 0.68347119 \\
\hline $\begin{array}{l}\text { What I wear and the way I } \\
\text { wear it show others my } \\
\text { attitudes. }\end{array}$ & 4 & $\begin{array}{c}0.87705801 \\
9\end{array}$ \\
\hline $\begin{array}{l}\text { My clothing reflects how I } \\
\text { feel about myself. }\end{array}$ & $\begin{array}{c}4.10606060 \\
6\end{array}$ & $\begin{array}{c}0.96282897 \\
1\end{array}$ \\
\hline $\begin{array}{l}\text { Dressing up makes me feel } \\
\text { important. }\end{array}$ & 3.96969697 & $\begin{array}{c}1.13638694 \\
6 \\
\end{array}$ \\
\hline $\begin{array}{l}\text { I care about what other } \\
\text { people think of how I look in } \\
\text { my clothes. }\end{array}$ & $\begin{array}{c}3.28787878 \\
8\end{array}$ & $\begin{array}{c}1.10613883 \\
6\end{array}$ \\
\hline $\begin{array}{l}\text { When I'm dissatisfied with a } \\
\text { part of my body, I wear } \\
\text { clothing that draws attention } \\
\text { away from it. }\end{array}$ & $\begin{array}{c}3.87878787 \\
9\end{array}$ & $\begin{array}{c}1.19634252 \\
3\end{array}$ \\
\hline $\begin{array}{l}\text { What I wear is consistent } \\
\text { with who I am. }\end{array}$ & $\begin{array}{c}3.71212121 \\
2 \\
\end{array}$ & $\begin{array}{c}1.03426155 \\
8 \\
\end{array}$ \\
\hline $\begin{array}{l}\text { I choose clothes that accent } \\
\text { the parts of my body that I } \\
\text { like. }\end{array}$ & $\begin{array}{l}3.45454545 \\
5\end{array}$ & $\begin{array}{c}1.05512402 \\
7\end{array}$ \\
\hline $\begin{array}{l}\text { I try to project a certain } \\
\text { image of myself to others } \\
\text { through my clothing. }\end{array}$ & $\begin{array}{c}3.25757575 \\
8\end{array}$ & 1.19370923 \\
\hline $\begin{array}{l}\text { I'm careful in wearing certain } \\
\text { styles or brands of clothing } \\
\text { because they affect how } \\
\text { people respect me. }\end{array}$ & $\begin{array}{c}2.87878787 \\
9\end{array}$ & $\begin{array}{c}1.30696538 \\
1\end{array}$ \\
\hline $\begin{array}{l}\text { When I feel good about } \\
\text { myself. I take care in getting } \\
\text { dressed. }\end{array}$ & $\begin{array}{c}4.12121212 \\
1\end{array}$ & $\begin{array}{c}1.00023307 \\
3\end{array}$ \\
\hline $\begin{array}{l}\text { My clothing is a part of me. } \\
\text { not just a simple possession. }\end{array}$ & $\begin{array}{c}3.72727272 \\
7 \\
\end{array}$ & $\begin{array}{c}1.01595660 \\
9\end{array}$ \\
\hline $\begin{array}{l}\text { The way I dress is important } \\
\text { in giving me a sense of being } \\
\text { in control of my life. }\end{array}$ & $\begin{array}{c}3.42424242 \\
4\end{array}$ & $\begin{array}{c}1.05335516 \\
8\end{array}$ \\
\hline $\begin{array}{l}\text { My self-confidence increases } \\
\text { when I dress appropriately. }\end{array}$ & $\begin{array}{c}4.06060606 \\
1 \\
\end{array}$ & $\begin{array}{c}1.00581062 \\
4 \\
\end{array}$ \\
\hline $\begin{array}{l}\text { Through my clothing, I can } \\
\text { show my values to others. }\end{array}$ & $\begin{array}{c}3.16666666 \\
7 \\
\end{array}$ & 1.21000106 \\
\hline $\begin{array}{l}\text { The way my clothing fits } \\
\text { affects the way I feel about } \\
\text { my body. }\end{array}$ & 4 & $\begin{array}{c}0.89442719 \\
1\end{array}$ \\
\hline $\begin{array}{l}\text { I feel good about myself } \\
\text { when I have something new } \\
\text { to wear. }\end{array}$ & 4.13636363 & 1.06534737 \\
\hline
\end{tabular}




\section{The Effects of Mood and Emotion on Consumer Purchase Behavior of Buying Clothes}

\begin{tabular}{|l|c|c|}
\hline $\begin{array}{l}\text { I avoid certain styles or } \\
\text { colors in clothing that do not } \\
\text { enhance my body build or } \\
\text { figure. }\end{array}$ & $\begin{array}{c}3.63636363 \\
6\end{array}$ & 1.19790026 \\
\hline $\begin{array}{l}\text { When I wear clothes that } \\
\text { make me feel good. I am } \\
\text { better able to talk with } \\
\text { others. }\end{array}$ & $\begin{array}{c}3.48484848 \\
5\end{array}$ & $\begin{array}{c}1.16674991 \\
4\end{array}$ \\
\hline $\begin{array}{l}\text { I try to buy clothing that } \\
\text { makes me feel attractive }\end{array}$ & $\begin{array}{c}4.07575757 \\
6\end{array}$ & 0.99708199 \\
\hline $\begin{array}{l}\text { My clothing gives others an } \\
\text { idea about my interests or } \\
\text { activities. }\end{array}$ & $\begin{array}{c}3.40909090 \\
9\end{array}$ & $\begin{array}{c}1.06665938 \\
2\end{array}$ \\
\hline $\begin{array}{l}\text { I wear certain clothing styles } \\
\text { to change the way my body } \\
\text { looks. }\end{array}$ & $\begin{array}{c}3.37878787 \\
9\end{array}$ & $\begin{array}{c}1.06359552 \\
1\end{array}$ \\
\hline
\end{tabular}

Table 2 How Does the Choice of Clothing Affects One's Moods and Emotions

22 questions are displayed in the above table with their calculated mean score and standard deviation (sample based, since the data is a sample of the overall population of people who could have been taken part in the research). 21 questions out of 22 questions have an average of higher than 3 which means the respondents mostly agreed with the questions answered. The tenth question which is asking the participants regarding the effect of wearing certain styles and brands on respect received from people had the lowest mean rating at 2.87, which indicates that the respondents did not feel that wearing certain style and brands would affect the level of respect received from their social circle.

A higher standard deviation indicates that respondents had more varying answers to the same question. For example, the same question which had the lowest mean rating also has the highest standard deviation which means a group of people strongly felt that wearing certain styles and brands would increase the level of respect received while a group of people strongly disagreed with this notion. This can be linked to people having different social groups, in which some of these social groups take the style and brand of clothing that is worn by the social group member very seriously and some social groups that do not pay much attention to the branding or style worn by the member. These groups can be identified as fashion centric social groups and non-fashion centric social groups.

The questions that gained rating of 4 or above indicates that respondents mostly agreed with how the clothing reflects their feelings and makes them feel good about themselves also they mostly agreed that when they are feeling good they take care in getting dressed and what they are wearing represents their attitudes to others. Respondents agreed that wearing appropriate clothing will increase their self-confidence and the way the clothes fit affects the way they feel about their body. Also, the respondents felt that having new clothes to wear gives them a good feeling and they try to buy the clothing that makes them feel more attractive.

The qualitative question that was being asked from participants reveals how they react and whether wearing cloths reflects their mood or emotion. Almost all the participants reveal answers to the question of whether they wear clothing that reflects their mood or changing their mood in a way such as "Yes, sometime when I'm not in the good mood, I try to wear something simple", "Sometimes that I am bored, I choose clothes to change my mood", "I wear kind of clothing which can improve my mood, like wearing in light colors or colorful dresses.", "I usually choose clothes that reflects my mood, if I am happy I wear pink and white and when I am not in a good mood I usually wear dark colors", "When I'm not in mood, I wear new cloths". From all 66 respondents, all were confirming and stating that when they want to change their mood they choose colorful clothes or the way that they choose their clothing reveals what is their feeling and emotion. The findings of the answered questions strongly indicate that mood of consumers/ individuals are positively changed and charged by wearing new and colorful cloths and construct connection with their attire which includes current trends, general comfort factors though gearing up the individuals' mood.

From the literature review, it was observed that a better understanding of how the fashion consumer uses clothing to reflect and manage emotion and mood when making decision about what to buy, may help to identify the relationship between clothing, mood and emotion.

\section{DISCUSSION AND LIMITATION}

The research methodology necessitated lengthy time commitments from the participants and therefore limited sample size, making generalization difficult. Based on the finding, the research requires further exploration of methods for practical application with a larger sample size. On the other hand, since mood and emotion are part of personality, later on with a bigger sample size, effect of clothing on personality can also be conducted.

Emotion and mood were shown to be managed and reflected through clothing with implications for assistance in consumer clothing decision. The result indicated strong relationship between mood and emotion. There are many other factors about dressing like color of the dress, print, quality of fabric and design of dress are important for the person and people do consider these factors. Thus, the questions answered by the respondents also reveals that when they want to change their mood, choosing brighter colors is a factor they choose in order to show their mood.

\section{CONCLUSION}

Emotions can directly influence intentions and behavior. Consumers use emotions to change the interpretation of the stimuli as well as their emotional reactions and behavior. The youth of today's era follows the current fashion trends and they believe that choosing what they wear influence and show their self-concept and revealing their moods and emotion. With the following findings of this paper, it considers that clothing translates the mood of an individual and it contributes more towards the negative or positive mood sense. Findings from the qualitative analysis of the questionnaire of this paper reveal that having on a new dress affects mood in a positive way because it develops the feeling of happiness. With this, the factors of clothing like color, fabric, print, design doesn't have a significant impact on the moods of the individuals particularly when they wear new dress. Clothing has a different mood appeal to every single entity. Choosing the type of clothes and its color plays an important role in changing the mood of a person. 
Clothing brings a change in a way people depict his/herself to others and communicates his/her personality via moods and emotions.

\section{REFERENCES}

1. Allen, Mark S. and Emma E. Walter. "Personality and body image: A systematic review." Body Image (2016): 79-88. Internet.

2. Asare, Thomas Obeng, Abdul-Fatahi Ibrahim and Asare Daniel Kwesi. "The Influence of Social and Psychological Factors on the Selection of Clothing among Female Students of Kumasi Polytechnic, Ghana." International Journal of Engineering Research and Reviews (2016): 20-29. PDF File.

3. Kang, Ju-Young M., Kim K.P. Johnson and Jieun Kim. "Clothing functions and use of lcothing to alter mood." International Journal of Fashion Design, Technology and Education (2013): 43-52. PDF File.

4. Moody, Wendy, Peter Kinderman and Pammi Sinha. "An exploratory study: relationships between trying on clothing, mood, emotion, personality and clothing preference." Journal of Fashion Marketing and Management (2010): 161-179. PDF file

5. Humphrey, C., Klaasen, M. and Creekmore, A.M. (2010), "Clothing and self-concept of adolescents", Journal of Home Economics, Vol. 63 No. 4, pp. 246-50

6. Laros, F.J.M. and Steenkamp, J-B.E.M. (2003), "Emotions in consumer behavior: a hierarchical

7. Kwon, Y-H. (2015), "Feeling toward one's clothing and self-perception of emotion, sociability, and work competency", Journal of Social Behavior and Personality, Vol. 9 No. 1, pp. 129-39.

\section{AUTHORS PROFILE}

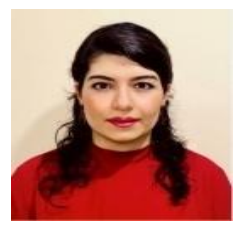

Ms. SepidehSamadi is working as a Business Faculty and Professional Faculty Development Rep and Research Coordinator in American College of Dubai for almost five years. She is a PhD Candidate in University of Bolotn, UK and her research intreset is mainly on Marketing and Consumer Behcavior. She has done several paper in Management, Project Management and Quality Assurance as well. Sepideh has completed her Master (MBA) and Bachelor (BBA) in University of Wollongong in Dubai. Her passion leads her to continue her career path as being an academy and writing scholarly research papers. 